\title{
Transfer of positive contextual control across different conditioned stimuli
}

\author{
DALE SWARTZENTRUBER and MARK E. BOUTON \\ University of Vermont, Burlington, Vermont
}

\begin{abstract}
A conditioned suppression experiment using rat subjects examined the extent to which contextual control of performance to a conditioned stimulus (CS) transfers to another CS trained in a similar manner. Two contextual discriminations were produced by alternating reinforced and nonreinforced tone CS presentations in Context $A$ and Context $B$, respectively, and reinforced and nonreinforced presentations of a light-off CS in Context $C$ and Context D, respectively. When the light-off CS was tested in Context A, the context facilitated suppression to the CS, suggesting transfer of Context A's modulating ability from the tone to the light-off. These results suggest that the tone discrimination was not due solely to the generation of configural cues between Context $A$ and the tone. They also support the similarity between contexts and other higher level modulators of CS performance, such as facilitators and occasion setters, whose modulating abilities have also been shown to transfer between separate but similarly trained CSs.
\end{abstract}

In a series of conditioned suppression experiments using rat subjects, Bouton and Swartzentruber (1986) trained a contextual discrimination in which two contexts came to control performance to a tone-conditioned stimulus (CS). Over alternating sessions, the tone was paired with an unconditioned stimulus (US) in Context $A$ and presented alone in Context $B$. The animals suppressed to the tone in A, but not in B, and when the tone was tested in a neutral third context, the intermediate suppression observed suggested that both A and B modulated suppression to the CS.

Such modulation could occur through a variety of mechanisms, including conditioned excitation or inhibition to the contexts summating with associative strength of the CS. However, subsequent experiments in Bouton and Swartzentruber's (1986) series demonstrated that the contexts did not control responding through their own demonstrable excitatory or inhibitory associations with the US. Context A neither enhanced suppression to a new excitatory CS nor blocked conditioning of a novel CS, and extensive nonreinforced exposure to this context did not reduce its ability to control responding. Likewise, Context B neither attenuated performance to another CS nor increased the rate at which a novel CS was conditioned in a test of supernormal conditioning, and the rate at which excitation was conditioned to B was not slow, as would be the case for a conditioned inhibitor. The results suggested that the actions of contexts may be similar to facilitators (e.g., Rescorla, 1985) or occasion setters (e.g., Holland, 1983), which control responding to CSs independently of their own associations with the US.

This research was supported by Grant BNS 86-07208 from the National Science Foundation. We thank Michael Fanselow for his comments on the manuscript. Send correspondence to Dale Swartzentruber, Department of Psychology, University of Vermont, Burlington, VT 05405.
An additional way to account for Context A's and B's modulating abilities is to assume that unique or configural cues arising from the CS-context compounds acquired their own associations with the US (see Rescorla, 1973). Associative strength to unique cues could control CS performance even where the contexts themselves appear associatively neutral. This mechanism could be ruled out if a context's ability to modulate responding to one CS transfers to another CS. Evidence of transfer would indicate that the context has modulating abilities that go beyond specific context-CS combinations.

The summation tests used by Bouton and Swartzentruber (1986), which provided an opportunity to examine transfer of contextual control, revealed no evidence of transfer. However, in the case of facilitators and occasion setters, transfer appears to occur only under certain circumstances. Both Holland (1983) and Rescorla (1985) similarly failed to find evidence that modulation transfers to a simple excitatory CS. On the other hand, Lamarre and Holland (1987) demonstrated transfer to a CS that had been trained in a separate occasion-setting relation, and Rescorla (1985) found that facilitation transfers to other stimuli that are currently under the influence of extinction or that have been trained in a separate facilitating relation (see also Davidson \& Rescorla, 1986; Holland, 1986, Experiment 3). Lamarre and Holland (1987) suggested that occasion setting may endow the CS with special properties that allow for its modulation by another occasion setter. Similarly, Bouton and Bolles (1985) and Bouton and King (1986) suggested the importance of CS ambiguity in allowing contextual control; CSs that are currently under the influence of extinction have received a mixed history of reinforcement and are more sensitive to the effects of the context.

The present experiment, therefore, tested the ability of a modulating context to transfer to another ambiguous CS that was trained in a similar discrimination. All animals 
received tone-US pairings in Context $A$ alternated with tone-alone presentations in Context B; they also received a similar treatment of a light-off CS in Contexts $C$ and D. The light-off CS was then tested in Context A. Transfer of Context A's modulating ability, as shown by its facilitation of suppression not only to the tone, but also to the light-off CS, would argue against the possibility that the tone discrimination was solved entirely by the generation of configural cues in Context $\mathbf{A}$. The test focused on Context A, the "positive" context, because positive features may be especially likely to gain control in discrimination learning (e.g., Jenkins \& Sainsbury, 1970).

\section{METHOD}

\section{Subjects}

The subjects were 8 male Wistar rats bred at the University of Vermont. They were 90 days old at the start of the experiment and were housed individually in standard stainless steel and wire mesh cages. The experiment was run at the same time each day during the light portion of a 12:12-h light:dark cycle. The animals were food deprived and maintained at $80 \%$ of their initial body weights throughout the experiment.

\section{Apparatus}

Four discriminably different contexts were provided by four sets of Skinner boxes housed in different rooms of the laboratory. The two sets of boxes that provided Contexts $A$ and $C$ (counterbalanced) have been described in detail elsewhere (e.g., Bouton, 1984; Bouton \& King, 1986; Bouton \& Swartzentruber, 1986). Each box from one set was constructed of aluminum, had fat (16-mm) bars perpendicular to the front wall as its floor, had the response lever situated to the right of a protruding food cup, and was scented with vinegar. Each box from the other set had clear acrylic plastic side walls with vertical black stripes, had 3$\mathrm{mm}$ steel bars parallel to the intelligence panel as its floor, had the response lever located to the left of a recessed food cup, and was scented with Vicks Vaporub.

The third and fourth contexts, which provided Contexts B and D (counterbalanced), were provided by two additional sets of four boxes located in other rooms. Each of these boxes measured $23 \times 13 \times 11 \mathrm{~cm}$. The walls and ceiling were constructed of clear acrylic plastic. Three walls were covered on the outside with black construction paper; the large (23$\mathrm{cm})$ front wall and ceiling were transparent. A small $(1 \times 1 \mathrm{~cm})$ food cup protruded from the back wall, $4.5 \mathrm{~cm}$ from the floor and $4.5 \mathrm{~cm}$ from the right side wall. A $1 \times 2.5 \mathrm{~cm}$ lever was located on the right side wall, centered $4.5 \mathrm{~cm}$ above the floor. The floor of the third context consisted of 3-mm bars staggered in such a way that the odd-numbered bars were mounted $6 \mathrm{~mm}$ above the even-numbered bars; distance between consecutive bars was $1.6 \mathrm{~mm}$. The bars were parallel to the narrow $(11-\mathrm{cm})$ right side wall. A dish containing $10 \mathrm{ml}$ of a $4 \%$ coconut extract solution (replaced daily) provided a distinctive scent cue. Horizontal white stripes, $1 \mathrm{~cm}$ in width and spaced $1 \mathrm{~cm}$ apart, lined the three black walls of these boxes. In the fourth context, the floors consisted of 3-mm bars, spaced $1.8 \mathrm{~cm}$ apart, that were mounted diagonal to the walls of the boxes. In these boxes, a $2 \%$ anise solution provided the distinctive scent cue.

Forty-five-mg Noyes food pellets (Formula A) were used to reinforce the leverpressing baseline in all four contexts. Illumination was provided by two 7.5 -W white incandescent bulbs $(100-\mathrm{V} \mathrm{ac})$ mounted on the ceiling of the sound-attenuation chamber, $28,27,25$, and $25 \mathrm{~cm}$ above the floors of Contexts A, B, C, and D, respectively. The CSs were 60-sec presentations of (1) a $3000-\mathrm{Hz}$ tone ( $80 \mathrm{~dB}$ re $20 \mu \mathrm{N} / \mathrm{m}^{2}[\mathrm{~A}]$ ), and (2) the offset of the overhead houselights (i.e., darkness). Background noise level was $65 \mathrm{~dB}$. The 0.5 - $\mathrm{sec} 0.6-\mathrm{mA}$ footshock US was provided by Grason-Stadler scramblers and shock sources. Computer and electromechanical programming equipment were housed in an adjoining, centrally located room.

\section{Procedure}

Baseline training. Each daily session was $90 \mathrm{~min}$ in duration. During the first session, each rat was trained to leverpress in either Con- text A or Context C. A food pellet was delivered for each of the first 50 responses, after which a variable-interval (VI) 90 -sec reinforcement schedule went into effect. On the next day, the procedure was repeated in a box from the other set (A or C). On Days 3 and 4, the rats continued to leverpress on the VI-90 schedule of reinforcement in Contexts $A$ and $C$, respectively. On Days 5 and 6, and again on Days 7 and 8, all animals alternated leverpressing on the VI-90 schedule in Contexts B and D, respectively. The VI-90 schedule was in effect for the remainder of the experiment.

Discrimination training. The next 36 daily sessions established two contextual discriminations. There were six 6-session cycles; all events were superimposed on the VI-90 schedule of reinforcement. On Session 1 of each cycle, the rats received fear conditioning with the tone CS in Context A: Each of four tone (T) presentations terminated in the onset of the footshock. Throughout the experiment, the intertrial interval (ITI) was variable with a mean of $20 \mathrm{~min}$. In Session 2, the tone was presented alone four times in Context B. Session 3 consisted of exposure to Context A with only the VI-90 schedule in effect (see Bouton \& Swartzentruber, 1986). On the 4th and 5th sessions of each cycle, the light-off (L) CS was similarly reinforced and nonreinforced in Contexts C and D. On Session 6, the animals leverpressed on the VI-90 schedule of reinforcement in Context $\mathbf{C}$. Formally, the cycles resulted in two contextual discriminations of the form AT+,BT-, and $\mathrm{CL}+, \mathrm{DL}-$; in each cycle, there were also $\mathrm{A}-$ and $\mathrm{C}-$ sessions.

Transfer test. Two subjects had to be discarded because a mishap in the colony room made their identities impossible to determine. Beginning on the day following the last session of the 6th cycle, the remaining rats were tested with the light-off CS in Contexts A and D. On the first session, 4 subjects received the light-off $C S$ four times alone in Context A; 2 subjects received the light-off CS in Context D. On the following session, the light-off CS was tested in the other context (A or D). Although complete counterbalancing was not possible following the loss of 2 rats, the results were completely consistent among individual subjects.

Data analysis. Suppression to the CS was indexed in terms of suppression ratios of the form $x /(x+y)$, where $x$ represents the number of leverpresses made during the 60-sec CS and $y$ the number of leverpresses made during the $60 \mathrm{sec}$ immediately preceding the CS (the pre-CS period). A suppression ratio of 0 indicates complete response suppression during the CS, whereas a ratio of 0.5 indicates no suppression of responding during the $\mathrm{CS}$.

\section{RESULTS}

The left portion of Figure 1 presents suppression to the tone and the light-off CS during the six discrimination cycles. The tone and light-off discriminations were analyzed with separate $2 \times 6$ (reinforcement condition $\times$ cycles) analyses of variance (ANOVAs). For the tone discrimination, there was a main effect of reinforcement $[F(1,5)$ $=65.75]$ and a cycles $\times$ reinforcement interaction $[F(5,25)=4.63]$. The cycles main effect was not significant $[F(5,25)=1.84]$. For the light-off discrimination, there were main effects of cycles $[F(5,25)=7.24]$ and reinforcement $[F(1,5)=21.34]$ and a cycles $\times$ reinforcement interaction $[F(5,25)=19.35]$. For both the tone and the light-off discriminations, simple effects tests on the last two cycles revealed significantly greater suppression in the reinforcement than in the nonreinforcement context $(F \mathrm{~s}>13.2)$. Contextual control of suppression to both stimuli was clearly established by the end of discrimination training.

Mean pre-CS scores during the cycles were 20.3, 19.3, 19.5, and 19.0, in Contexts A, B, C, and D, respectively. A one-way ANOVA revealed no significant differences in leverpress rates across contexts $[F(3,15)<1]$. 


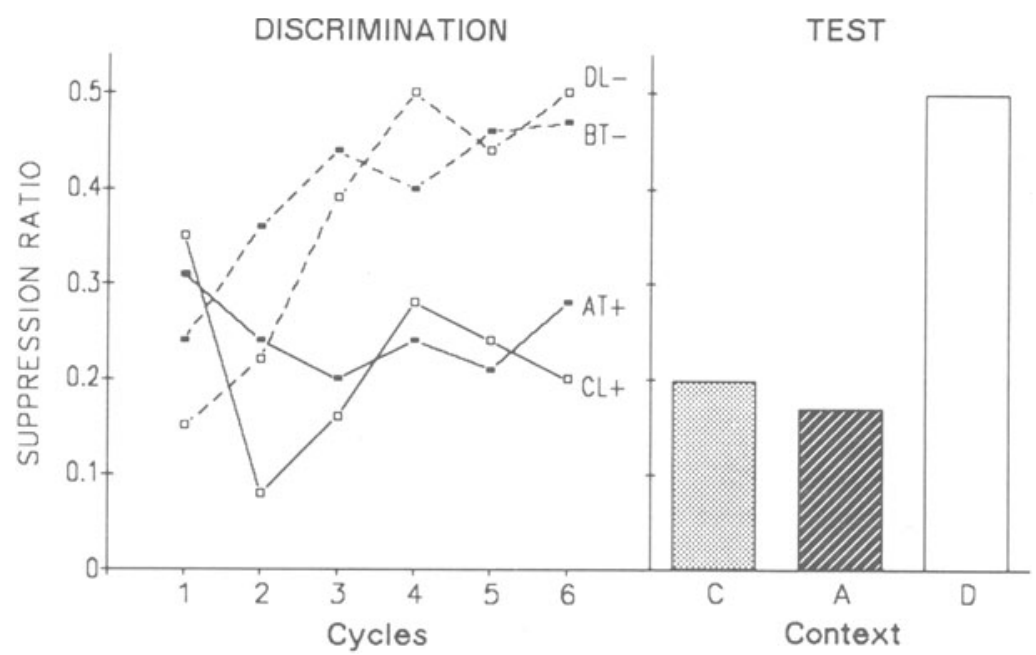

Figure 1. Mean suppression to the tone $(T)$ and light-off $(L)$ conditioned stimuli during discrimination training (left) and during the transfer test (right). $(+=$ reinforced sessions; - = nonreinforced sessions; $\mathbf{C}, \mathbf{A}$, and $\mathbf{D}=$ contexts.)

The data from the transfer test are presented in the right portion of Figure 1, where mean suppression to the lightoff CS is shown during the final session of discrimination training in Context $\mathrm{C}$, and during the nonreinforced test sessions in Contexts $A$ and $D$. The figure suggests that the ability of Context A to modulate suppression to the tone transferred to the light-off. This was confirmed by a within-subjects ANOVA, which revealed a significant difference in suppression in the three contexts $[F(2,10)=33.13]$. Pairwise comparisons revealed more suppression in the transfer context (Context A) than in the context of nonreinforcement (Context D) $[F(1,10)=$ 53.9], and suppression in the transfer context did not differ from that in the light-off's original context of reinforcement (Context $C)[F(1,10)<1]$. The pattern of marked and equivalent suppression in $A$ and $C$ with no suppression in D was evident in each subject. Thus, neither the sequence of testing (Contexts $A$ and $D$ ) nor the actual boxes providing the contexts influenced the results.

Mean pre-CS rates were 20.7, 27.2, and 23.8 in Contexts C, A, and D, respectively. An ANOVA revealed significant differences across contexts $[F(2,10)=4.41]$; the pre-CS rate was significantly higher in Context $A$ than in Context $C[F(1,10)=8.73]$, but did not differ from the rate in Context $\mathrm{D}[F(1,10)=2.41]$.

\section{DISCUSSION}

Previous research has established that, following the discrimination procedure used with the tone in Contexts $A$ and $B$, Context A positively modulates suppression to the tone when suppression in $\mathbf{A}$ is compared with suppression in a neutral third context (Bouton \& Swartzentruber, 1986). The present results suggest that this ability may transfer to another CS trained in a similar discrimination. The data strongly suggest that Context A's ability to modulate suppression to the tone is not due to the conditioning of a Context A-tone configural cue, because excita- tion to such a cue should not affect responding to the light-off. Context $\mathbf{A}$ appears to acquire some signaling ability that transcends its affect on the tone.

At least three mechanisms could predict the transfer shown here. First, the reinforcement context itself could control performance through its own associations with the US. Thus, contextual control could result from excitatory associations between Context $A$ and the US summating with excitation to the CS. However, direct tests of excitation in A following the discrimination procedure used here have consistently failed to provide support for this mechanism (Bouton \& Swartzentruber, 1986). More generally, simple context-US associations are neither necessary (e.g., Bouton \& Swartzentruber, 1986) nor sufficient (Bouton, 1984; Bouton \& King, 1986) for a context to control responding to a CS.

Second, as suggested by Bouton and Swartzentruber (1986), the contexts may control responding by signaling, or setting the occasion for, the corresponding CS-US relations. By setting the occasion for a positive CS-US relation, Context A may resolve the CS ambiguity that occurs from a conditioning history that contains both reinforced and nonreinforced episodes. The present results suggest that this context may set the occasion, not only for the original CS, but also for CSs with similar conditioning histories.

Third, the contexts in which the CSs were nonreinforced could have been partly responsible for the contextual control and transfer observed here. In principle, there could have been relatively strong suppression to the light-off in Context $A$ if some attenuating process in Context D (negative occasion setting, inhibition, or inhibitory configural conditioning) were in primary control of suppression to the light-off. However, direct tests of modulation by Context A clearly suggest that it facilitates tone suppression in the present discrimination procedure (Bouton \& Swartzentruber, 1986, Experiments 1 and 3). Thus, although Context D might indeed attenuate suppression to the light-off, it is unlikely that this alone would account for the substantial suppression observed in Context $\mathbf{A}$.

Although prior research has provided no evidence that context excitation is the mechanism controlling the present discrimination, it is worth reiterating that we would expect the same results if Context A had merely become a conditioned excitor: Excitatory contexts do enhance suppression to CSs that are otherwise under the influence of extinction (e.g., Bouton, 1984; Bouton \& King, 1986). However, context excitation is not sufficient to modulate performance to CSs that have been continuously or partially reinforced (Bouton \& King, 1986). The demonstration that excitatory contexts control performance to a specific class of 
CSs, namely those that are under some form of discriminative control, suggests that contexts may control in a manner different from ordinary excitors. This role is similar to that of facilitators and occasion setters, whose properties also appear to transfer only to CSs that are under the influence of extinction (Rescorla, 1985) or that have been trained in a separate occasion-setting discrimination (Davidson \& Rescorla, 1986; Lamarre \& Holland, 1987).

\section{REFERENCES}

Bouton, M. E. (1984). Differential control by context in the inflation and reinstatement paradigms. Journal of Experimental Psychology: Animal Behavior Processes, 10, 56-74.

Bouton, M. E., \& Bolles, R. C.(1985). Contexts, event-memories, and extinction. In P. D. Balsam \& A. Tomie (Eds.), Context and learning (pp. 133-166). Hillsdale, NJ: Erlbaum.

Bouton, M. E., KING, D. A.(1986). Effect of context on performance to conditioned stimuli with mixed histories of reinforcement and nonreinforcement. Journal of Experimental Psychology: Animal Behavior Processes, 12, 1-12.

Bouton, M. E., Swartzentruber, D. (1986). Analysis of the associative and occasion-setting properties of contexts participating in a Pavlovian discrimination. Journal of Experimental Psychology: Animal Behavior Processes, 12, 333-350.
Davidson, T. L., Rescorla, R. A. (1986). Transfer of facilitation in the rat. Animal Learning \& Behavior, 14, 380-386.

Holland, P. C. (1983). Occasion setting in Pavlovian feature positive discriminations. In M. L. Commons, R. J.Herrnstein, \& A. R. Wagner (Eds.), Quantitative analyses of behavior: Discrimination processes (Vol. 4, pp. 183-206). New York: Ballinger.

Holland, P. C. (1986). Temporal determinants of occasion setting in feature-positive discriminations. Animal Learning \& Behavior, 14, 111-120.

Jenkins, H. M., Sainsbury, R. S. (1970). Discrimination learning with the distinctive feature on positive or negative trials. In D. Mostofsky (Ed.), Attention: Contemporary theory and analysis (pp. 239-274). New York: Appleton-Century-Crofts.

LAmarre, J., \& Holland, P. C. (1987). Transfer of inhibition after serial feature negative discrimination training. Learning \& Motivation, 18, 319-342.

Rescorla, R. A.(1973). Evidence for "unique stimulus" account of configural conditioning. Jourmal of Comparative \& Physiological Psychology, 85, 331-338.

Rescorla, R. A. (1985). Conditioned inhibition and facilitation. In R. R. Miller \& N. E. Spear (Eds.), Information processing in animals: Conditioned inhibition (pp. 299-326). Hillsdale, NJ: Erlbaum.

(Manuscript received April 26, 1988.) 